\title{
Notification about influenza vaccination in Belgium: a descriptive study of how people want to be informed
}

\author{
*Inès Van Rossema, Jan Vandevoorde ${ }^{a}$, Ronald Buyl', Sander Deridderc, Dirk Devroey ${ }^{\mathrm{a}}$ \\ a Department of Family Practice, Dutch-speaking University of Brussels (VUB), Brussels, Belgium \\ b Department of Biostatistics and Medical Informatics, Dutch-speaking University of Brussels (VUB), Brussels, Belgium \\ Department of Chemical Engineering, Dutch-speaking University of Brussels (VUB), Brussels, Belgium
}

Received 18th August 2011; revised 21st October 2011; accepted 19th December 2011; online 19 th March 2012

\begin{abstract}
Background: Influenza causes a substantial socioeconomic burden. In Belgium, only $54 \%$ of the target group receives an annual vaccination. Patient reminder/recall systems are effective in improving vaccination rates in primary care, but little is known about patients' preferences on notification of influenza vaccination.

Aims: To evaluate whether general practice patients wish to be notified of the possibility of receiving influenza immunisation, and how. Methods: In January 2008, 750 questionnaires were handed out to all consecutive patients aged >18 years in three Belgian general practices. Main outcome measures were the percentage wanting to be notified, demographic and medical factors influencing the information needs of the patients and the specific way in which patients wanted to be notified.

Results: About $80 \%$ of respondents wanted to be notified of the possibility of influenza vaccination. Logistic regression analysis showed that those who had previously been vaccinated particularly wished to be notified, both in the total population (OR $4.45 ; 95 \% \mathrm{Cl} 2.87$ to $6.90 ; p<0.0001)$ and in the subgroup of high-risk individuals (OR 9.05; $95 \% \mathrm{Cl} 4.47$ to $18.33 ; p<0.0001$ ). More than $85 \%$ of the participants wanted to be informed by their family physician, mostly during a consultation regardless of the reason for the encounter. The second most preferred option was a letter sent by the family physician enclosing a prescription.

Conclusions: The majority of general practice patients want to be notified of the possibility of influenza vaccination. More than $85 \%$ of participants who wanted to be notified preferred to receive this information from their family physician, mostly by personal communication during a regular visit. However, since a large minority preferred to be addressed more proactively (letter, telephone call, e-mail), GPs should be encouraged to combine an opportunistic approach with a proactive one.

(C) 2012 Primary Care Respiratory Society UK. All rights reserved.

I Van Rossem et al. Prim Care Respir J 2012; 21(3): 308-312

http://dx.doi.org/10.4104/pcrj.2012.00012
\end{abstract}

Keywords descriptive study, family practice, influenza, reminder systems, vaccination

See linked editorial by Mowbray and Rubin on pg 248

The full version of this paper, with online appendix,

is available online at www.thepcrj.org

\section{Introduction}

Influenza is a highly infectious acute respiratory illness. Worldwide, $20 \%$ of children and $5 \%$ of adults develop symptomatic influenza each year. Influenza causes acute respiratory symptoms combined with fever and myalgia. The clinical features typically last for 3-5 days, although the cough, tiredness and malaise may last for 1-2 weeks. Influenza outbreaks occur annually across the world, causing increased morbidity and hospitalisation rates and excess mortality. Elderly people and high-risk patients with concomitant chronic diseases are most susceptible to complications of influenza, causing a substantial socioeconomic burden for society. ${ }^{1,2}$ Pregnant women and their newborn infants are also at increased risk of developing serious complications. ${ }^{3}$

Influenza-related clinical complications are predominantly respiratory, such as acute bronchitis, bacterial or viral pneumonia, and exacerbations of asthma and chronic obstructive pulmonary disease (COPD). Non-respiratory complications such as febrile

\footnotetext{
* Corresponding author: Miss Inès Van Rossem, Department of Family Practice, Dutch-speaking University of Brussels (Vrije Universiteit Brussel), Laarbeeklaan 103, B-1090 Brussels, Belgium. Tel: +32 24774311 Fax: +32 24774301 E-mail: ivrossem@vub.ac.be.
} 


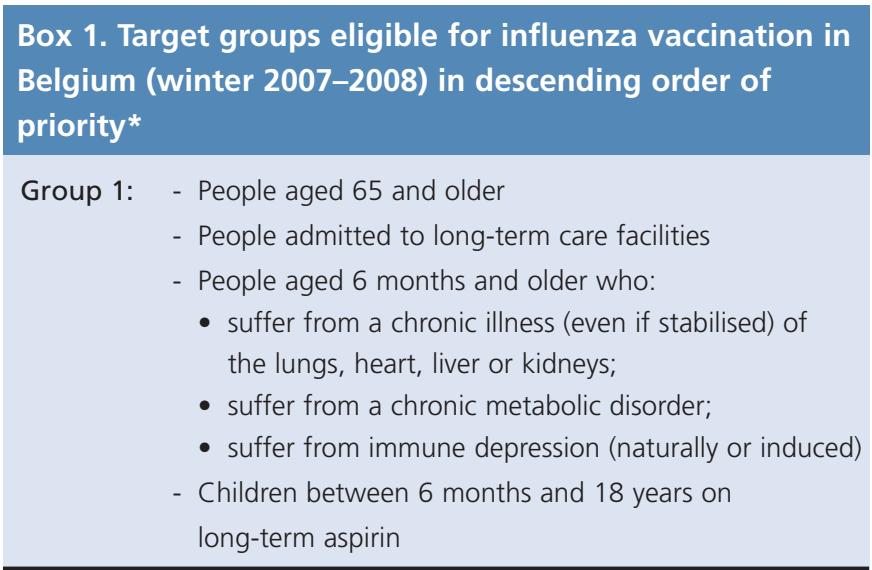

Group 2: Health care personnel in direct contact with people from Group 1

Group 3: Pregnant women (second and third trimester)

Group 4: People between 50 and 65 years of age, even if they do not suffer from any of the chronic diseases mentioned above (especially smokers, excessive drinkers or obese people).

* Issued by the Superior Health Council (the scientific advisory body of the Belgian Federal Public Service of Health, Food Chain Safety and Environment).

convulsions (in children), heart failure, myositis, encephalitis, Guillain-Barré syndrome and toxic shock syndrome occur less frequently. ${ }^{4}$

Seasonal influenza vaccination has been proved to be effective and safe. In adults, the efficacy of the vaccine in preventing influenza is estimated at $77 \%$. Vaccination of patients with chronic lung disease, cardiovascular disease and diabetes reduces hospital admissions, complications and mortality. ${ }^{1}$ In pregnant women, maternal influenza immunisation has a substantial protective effect in both mothers and their young infants up to 6 months of age. ${ }^{5}$

The most common adverse effects of vaccination are soreness at the immunisation site, fever, malaise and myalgia. Immediate allergic reactions are very rare but anaphylaxis can occur after administration of a vaccine, most frequently caused by hypersensitivity to residual egg protein. ${ }^{1}$

In Belgium, a list of high-risk groups eligible for influenza vaccination is issued yearly by the Superior Health Council, the scientific advisory body of the Belgian Federal Public Service of Health, Food Chain Safety and Environment (Box 1). ${ }^{6}$

In Belgium, only $54 \%$ of the population eligible for immunisation currently receive an annual influenza vaccine. ${ }^{7}$ Using a computer-supported strategy, the general practitioner (GP) can attain a vaccination coverage of $70 \%{ }^{8}$

Patient reminder/recall systems have proved to be effective in improving vaccination rates in primary care settings. All types of patient reminders are effective (e.g. postcards, letters, telephone calls), with telephone reminders being the most effective but most costly. ${ }^{9}$ To increase influenza vaccination rates in those aged 60 years and older in the community, personalised postcards or telephone calls are effective, and home visits and facilitators may be effective. ${ }^{10}$ The use of multiple reminders also appears to be more effective than single reminders. ${ }^{11}$ Provider reminder systems that inform vaccine providers that the individual clients are due for vaccination are also effective in improving targeted vaccination coverage among the elderly ${ }^{12}$ and high-risk adults. ${ }^{13}$

The Flemish Agency for Care and Health develops and implements the health policy of the Flemish community in Belgium. This includes the organisation of a yearly influenza vaccination campaign executed by the 'Vlaams Griepplatform'. This task force includes representatives of family physicians, pharmacists, health insurance companies, the Diabetes Association and associations for the elderly. Influenza immunisation is promoted by providing flyers and posters for public places, family physicians and pharmacists. They also advertise in papers and magazines and organise press conferences. In parallel, 'Domus Medica', the scientific organisation of Flemish family physicians, issues guidelines for good medical practice. They advise family physicians to follow a staged approach in promoting influenza vaccination among high-risk patients by (1) offering the influenza vaccine opportunistically; (2) sending out invitations; and (3) telephoning non-responders.

However, little is known about patients' preferences on notification about influenza vaccination.

This study aims to evaluate whether family practice patients wish to be notified of the possibility of receiving an influenza immunisation. In addition, the influence of age, gender, language group (Dutch/French), presence of risk factors, number of risk factors and influenza vaccination history on whether or not people wanted to be notified was evaluated. Finally, the specific manner in which the participants preferred to be notified was assessed.

\section{Methods}

In January 2008 a questionnaire was handed out by GPs to 750 consecutive patients aged $>18$ years in three Belgian family practices (250 patients in each participating practice). The participating practices were demographically spread (metropolitan, urban and rural environment). None had a prior vaccination policy and vaccination had been previously offered in an opportunistic manner.

The questionnaire contained questions about demographic characteristics, medical indications for influenza vaccination, and opinions on how people preferred to be notified of the possibility of influenza immunisation. Since, to the best of our knowledge, there are no existing validated questionnaires which address the preferred manner of notifying patients about influenza vaccination, the questionnaire was self-developed (see Appendix 1, available online at www.thepcrj.org). Age, gender, language group (Dutch/French), the presence of risk factors, number of risk factors and influenza vaccination history were examined for their influence on patients' information needs using both univariate and multivariate logistic regression analyses. Analyses were performed on the total study population and on the high-risk population.

Data were analysed with the Statistical Package for Social Science version 16.0 (SPSS, Chicago, IL, USA). 


\section{Results}

Of a total of 750 questionnaires, 132 (18\%) were excluded because they were incomplete. A total of 618 forms were analysed. The characteristics of the study population are shown in Table 1. The median age was 50 years and 59\% were women. Of the 618 participants included in the study, 290 (47\%) had one or more reasons to be eligible for immunisation (target group). Participants who had previously received at least one influenza vaccination represented $57 \%$ and $75 \%$ of the total population and the target group, respectively.

\section{Need for notification of the possibility of influenza immunisation}

Table 2 shows that, overall, about $80 \%$ of the total population wanted to be notified of the possibility of influenza vaccination. The need for notification was highest in the previously vaccinated group and in the target group (90\% and $84 \%$, respectively). However, it was significantly lower in the group of subjects who had never been vaccinated before, both in the total study population $(66 \%$, $p<0.0001)$ and in the target group (57\%, p<0.0001).

Table 3 shows the results of the univariate and multivariate

\section{Table 1. Characteristics of the study population}

\begin{tabular}{ll} 
Total population, $\mathrm{n}(\%)$ & $618(100.0)$ \\
Age, mean (SD), yrs & $50.4(18.0)$ \\
Age, median, yrs & 50 \\
Age, IQR, yrs & 30 \\
Vaccination history & \\
$\quad$ Never vaccinated before, $\mathrm{n}(\%)$ & $239(38.7)$ \\
$\quad$ Previously vaccinated, $\mathrm{n}(\%)$ & $351(56.8)$ \\
Unknown vaccination history, $\mathrm{n}(\%)$ & $28(4.5)$ \\
\hline Target group, $\mathrm{n}(\%)^{*}$ & $290(46.9)$ \\
Age, mean (SD), yrs & $61.1(17.2)$ \\
Age, median, yrs & 67 \\
Age, IQR, yrs & 24 \\
Reason to belong to the target group & \\
65 years and older, $\mathrm{n}(\%)^{*}$ & $160(25.9)$ \\
Chronic heart disease, $\mathrm{n}(\%)^{*}$ & $93(15.0)$ \\
Chronic lung disease, $\mathrm{n}(\%)^{*}$ & $52(8.4)$ \\
Diabetes mellitus, $\mathrm{n}(\%)^{*}$ & $43(7.0)$ \\
Chronic kidney disease, $\mathrm{n}(\%)^{*}$ & $5(0.8)$ \\
Chronic liver disease, $\mathrm{n}(\%)^{*}$ & $6(1.0)$ \\
Immune depression, $\mathrm{n}(\%)^{*}$ & $12(1.9)$ \\
Pregnant, $\mathrm{n}(\%)^{*}$ & $5(0.8)$ \\
Healthcare personnel, $\mathrm{n}(\%)^{*}$ & $38(6.1)$ \\
Vaccination history & $70(24.1)$ \\
Never vaccinated before, $\mathrm{n}(\%) \dagger$ & $216(74.5)$ \\
Previously vaccinated, $\mathrm{n}(\%) \dagger$ & $4(1.4)$ \\
Unknown vaccination history, $\mathrm{n}(\%) \dagger$ & \\
\hline
\end{tabular}

$\mathrm{IQR}=$ interquartile range, $\mathrm{SD}=$ standard deviation.

*\% of the total population $(n=618)$. Some patients had multiple risk factors. t\% of the target group $(n=290)$.
Table 2. Need for notification of influenza vaccination in different subpopulations

$\%$ of participants wanting to be notified

\begin{tabular}{cc}
\hline Total population & 80.3 \\
Never vaccinated before & 66.1 \\
Previously vaccinated & 89.7 \\
\hline Target group & 84.1 \\
Never vaccinated before & 57.1 \\
Previously vaccinated & 92.7
\end{tabular}

logistic regression analyses, with 'wanting to be informed' as the dependent variable. The univariate analysis shows that patients were more likely to request notification if they were older, male, had been vaccinated before and had more risk factors. In the multivariate analysis, 'previously vaccinated' remained an independent predictor for the wish to be notified about influenza vaccination, both in the total population (OR 4.45; 95\% CI 2.87 to $6.90 ; p<0.0001)$ and in the subgroup of the target group (OR 9.05; $95 \% \mathrm{Cl} 4.47$ to $18.33 ; \mathrm{p}<0.0001)$. In the target group, men wanted to be notified more than women (OR 3.07; 95\% Cl 1.30 to 7.23 ; $\mathrm{p}=0.01$ ).

\section{Preferred method of being notified}

Table 4 shows the specific way in which the participants preferred to be notified of the possibility of influenza vaccination. More than $85 \%$ of the total population wanted to be notified by their family physician, mostly during a regular consultation regardless of the reason for the encounter. The second most preferred option was a letter sent by the family physician enclosing a prescription for the influenza vaccine. Similar results were found in the target group.

\section{Discussion}

\section{Main findings and interpretation in relation to previously published work}

This study shows that about $80 \%$ of family practice patients wanted to be notified of the possibility of receiving an influenza vaccine. However, the wish to be notified was strongest in patients who had previously been vaccinated at least once (90\%). Subjects who had never been vaccinated expressed less need for notification $(p<0.0001)$ in both the total population $(66 \%)$ and in the target group (57\%). Even though the present study did not ask about the reasons for refusal of notification, a possible explanation for this finding may be that previously vaccinated patients are already convinced of the usefulness of the vaccine whereas some people have already made up their mind about their refusal to be vaccinated and do not want to be asked again. A subgroup analysis of patients who had never been vaccinated within the target group showed that older people in particular did not want further notification (data not shown). It may be difficult to convince these patients in the future of the benefits of immunisation. A study in the USA in people aged 65 years and older showed that the most frequently self-reported reasons for not receiving an influenza vaccine were 
Table 3. Odds ratios estimated by logistic regression analysis for the wish to be notified about influenza vaccination

\begin{tabular}{|c|c|c|c|c|c|c|}
\hline \multirow[t]{2}{*}{ Variable } & \multicolumn{3}{|l|}{ Univariate } & \multicolumn{3}{|l|}{ Multivariate } \\
\hline & Odds ratio & $95 \% \mathrm{Cl}$ & $p$ value & Odds ratio & $95 \% \mathrm{Cl}$ & $\mathrm{p}$ value \\
\hline \multicolumn{7}{|l|}{ Total population } \\
\hline Male sex & 1.58 & 1.04 to 2.40 & 0.03 & & & \\
\hline Age & 1.01 & 1.00 to 1.03 & 0.01 & & & \\
\hline Target person & 1.60 & 1.07 to 2.40 & 0.02 & & & \\
\hline Previously vaccinated & 4.49 & 2.89 to 6.94 & $<0.0001$ & 4.45 & 2.87 to 6.90 & $<0.0001$ \\
\hline \multicolumn{7}{|l|}{ Target group } \\
\hline Language (Dutch/French) & 1.06 & 0.56 to 2.03 & NS & & & \\
\hline Male sex & 3.41 & 1.53 to 7.62 & 0.003 & 3.07 & 1.30 to 7.23 & 0.01 \\
\hline Age & 1.01 & 0.99 to 1.03 & NS & & & \\
\hline
\end{tabular}

Table 4. Preferred notification methods for patients who wished to be informed ( $n=496$ in total population, $\mathrm{n}=\mathbf{2 4 4}$ in target group)

\begin{tabular}{lll} 
& $\begin{array}{l}\text { Total } \\
\text { population, } \\
\text { n (\%) }\end{array}$ & $\begin{array}{l}\text { Target } \\
\text { group, } \\
\mathrm{n}(\%)\end{array}$ \\
\hline General practitioner & $424(85.5)$ & $213(87.3)$ \\
\hline Personal communication during visit & $248(50.0)$ & $146(59.8)$ \\
\hline Letter with enclosed prescription & $81(16.3)$ & $36(14.7)$ \\
\hline E-mail & $41(8.3)$ & $8(3.3)$ \\
\hline Telephone call & $28(5.6)$ & $14(5.7)$ \\
\hline Letter without prescription & $18(3.6)$ & $7(2.9)$ \\
\hline Posters and leaflets in waiting room & $8(1.6)$ & $2(0.8)$ \\
\hline Media & $12(2.4)$ & $3(1.2)$ \\
\hline Newspapers and magazines & $7(1.4)$ & $3(1.2)$ \\
\hline Television & $3(0.6)$ & $0(0.0)$ \\
\hline Radio & $2(0.4)$ & $0(0.0)$ \\
\hline Municipality & $10(2.0)$ & $5(2.0)$ \\
\hline Letter from the municipal government & $8(1.6)$ & $5(2.5)$ \\
\hline Posters and leaflets in public places & $2(0.4)$ & $0(0.0)$ \\
\hline Pharmacist & $7(1.4)$ & $5(2.0)$ \\
\hline Personal communication during visit & $5(1.0)$ & $4(1.6)$ \\
\hline Posters and leaflets in the pharmacy & $2(0.4)$ & $1(0.4)$ \\
\hline Others* & $43(8.7)$ & $18(7.4)$ \\
\hline *In this category, all participants mentioned 'the employer'. & \\
\hline & &
\end{tabular}

not knowing that the vaccine was needed and concerns that the vaccination might cause influenza or side effects. ${ }^{14}$

A rather surprising finding was that, in the target group, men wanted to be notified about influenza vaccination more than women. We found no significant differences in vaccination history and risk factors between sexes that could explain this finding.

More than $85 \%$ of the participants who wanted to be notified expressed their wish to receive information on influenza vaccination from their family physician, mostly by a personal communication during a regular visit. An enquiry on influenza immunisation by the OCL (Ondersteuningcel Logo's, an organisation engaged in preventive health care in Belgium) showed that family physicians initiated the vaccination in $72 \%$ of cases. ${ }^{15}$ In the same study, 59\% of those who had never been vaccinated stated that their family physician could persuade them to be immunised. Advice concerning influenza vaccination given by the doctor is one of the most important predictive factors for vaccination in elderly patients and those at risk. ${ }^{16}$ Our study results confirm the determining role of the family physician in influenza vaccination.

\section{Strengths and limitations of this study}

The main strength of this study is that, to the best of our knowledge, this is the first study to investigate patients' opinions on notification of the possibility of influenza vaccination. However, there are some weaknesses. Because of practical considerations, patients visited at home were not included in the study. We acknowledge that the broad inclusion criteria of this study may have led to the inclusion of subjects never really intended for vaccination, who were therefore answering hypothetical questions. However, certain conditions making subjects eligible for vaccination can be present at a young age (e.g. pregnancy, healthcare personnel, early-onset diabetes). Moreover, the presence of indications for influenza vaccination can change with time, and subjects who are not presently eligible for vaccination can become so in the future. In addition, patients' risk factors and vaccination history were self-declared. Finally, it should be emphasised that this survey was held in a group of family practice patients, which may have influenced their choice 
for the family physician as their main potential informer. However, notifying patients in their preferred way may lead to an increase in vaccination coverage.

Implications for future research, policy and practice A larger population-based study could put a new perspective on this issue.

Our findings have some implications for clinical practice. Although the most preferred manner of notification was a personal communication by the GP during a visit (an opportunistic approach), a large minority preferred to be addressed more proactively (by a letter sent by the GP with or without an enclosed prescription, e-mail or telephone call). GPS should be encouraged to combine an opportunistic approach with a proactive one.

Our data did not reveal differences in the way people wanted to be notified according to their vaccination history or their eligibility for vaccination. There is therefore no need for different information strategies in the different subgroups analysed.

\section{Conclusions}

This study showed that most family practice patients want to be notified of the possibility of influenza vaccination, especially if they have previously been vaccinated. Notifying patients in their preferred way may lead to an increase in vaccination coverage. More than $85 \%$ of the participants preferred to receive the information from their family physician, mostly by a personal communication during a regular visit. Since a large minority preferred to be addressed more proactively (by letter, telephone call or e-mail), GPs should be encouraged to combine an opportunistic approach with a proactive one.

\section{Handling editor Dianne Goeman Statistical review Gopal Netuveli}

Acknowledgements The authors thank all the participating family physicians for the registrations and also like to thank Lieve Van de Block and Erwin Van De Vyver for their cooperation.

Conflicts of interest The authors declare that they have no conflicts of interest in relation to this article.

Contributorship IVR: conception, design, analysis and interpretation of data, drafting of the manuscript and critical revision. JV: design, analyses and interpretation of data, drafting of the manuscript and critical revision. RB: statistical analyses. SD: interpretation of data and critical revision. DD: critical revision.

Funding None.

\section{References}

1. Nicholson KG, Wood JM, Zambon M. Influenza. Lancet 2003;362(9397):1733-45. http://dx.doi.org/10.1016/S0140-6736(03)14854-4
2. Meier CR, Napalkov PN, Wegmuller Y, Jefferson T, Jick H. Population-based study on incidence, risk factors, clinical complications and drug utilisation associated with influenza in the United Kingdom. Eur J Clin Microbiol Infect Dis 2000;19(11):834-42. http://dx.doi.org/10.1007/s100960000376

3. Tamma PD, Ault KA, del RC, Steinhoff MC, Halsey NA, Omer SB. Safety of influenza vaccination during pregnancy. Am J Obstet Gynecol 2009;201(6):547-52. http://dx.doi.org/10.1016/j.ajog.2009.09.034

4. Turner D, Wailoo A, Nicholson K, Cooper N, Sutton A, Abrams K. Systematic review and economic decision modelling for the prevention and treatment of influenza $A$ and B. Health Technol Assess 2003;7(35):1-170.

5. Zaman K, Roy E, Arifeen SE, et al. Effectiveness of maternal influenza immunization in mothers and infants. N Engl J Med 2008;359(15):1555-64. http://dx.doi.org/10.1056/NEJMoa0708630

6. Federale Overheidsdienst Volksgezondheid: Hoge gezondheidsraad. Adviezen en Brochures van de HGR: Vaccinatie tegen seizoensgebonden griep winterseizoen 2007-2008 [Superior Health Council. Advises and Brochures of the SHC: Vaccination against seasonal influenza winter season 2007-2008]. Rapportnummer: 8354. htpp://www.iph.fgov.be (accessed 1 March 2011).

7. Gisle L, Hesse E, Drieskens S, Demarest S, Van der Heyden J, Tafforeau J. Gezondheidsenquête België, 2008, Rapport II - Leefstijl en Preventie [Health interview survey, Belgium,2008]. Operationele Directie Volksgezondheid en surveillance, 2010, Brussel,Wetenschappelijk Instituut Volksgezondheid, ISSN: 2032-9172 Depotnummer. D/2010/2505/16 - IPH/EPI REPORTS No 2010/009. htpp://www.iph.fgov.be (accessed 1 March 2011).

8. Hak E, Van Essen GA, Stalman WA, et al. Improving influenza vaccination coverage among high-risk patients: a role for computer-supported prevention strategy? Fam Pract 1998;15(2):138-43. http://dx.doi.org/10.1093/fampra/15.2.138

9. Jacobson VJ, Szilagyi P. Patient reminder and patient recall systems to improve immunization rates. Cochrane Database Syst Rev 2005;20(3). http://dx.doi.org/10.1002/14651858

10. Thomas RE, Russell M, Lorenzetti $D$. Interventions to increase influenza vaccination rates of those 60 years and older in the community. Cochrane Database Syst Rev 2010;8(9). http://dx.doi.org/10.1002/14651858

11. Szilagyi P, Bordley C, Vann JC, et al. Effect of patient reminder/recall interventions on immunization rates: a review. JAMA 2000;284(14):1820-7. http://dx.doi.org/10.1001/jama.284.14.1820

12. Thomas RE, Russell M, Lorenzetti $D$. Systematic review of interventions to increase influenza vaccination rates of those 60 years and older. Vaccine 2010;28(7):1684701. http://dx.doi.org/10.1016/.vaccine.2009.11.067

13. Ndiaye $S$, Hopkins $D$, Shefer $A$, et al. Interventions to improve influenza, pneumococcal polysaccharide, and hepatitis B vaccination coverage among high-risk adults. A systematic review. Am J Prev Med 2005;28(5):248-64. http://dx.doi.org/10.1016/j.amepre.2005.02.016

14. Center for Disease Control and Prevention. Influenza vaccination and self-reported reasons for not receiving influenza vaccination among Medicare beneficiaries aged >65 years-United States, 1991-2002. MMWR Morb Mortal Wkly Rep 2004;53(43):1012-15

15. Baeten R. Griepvaccinatie, de centrale rol van de huisarts [Influenza vaccination, the central role of the general practitioner]. Vaxinfo 2008:51:1.

16. Leads from the MMWR. Adult immunization: knowledge, attitudes, and practices DeKalb and Fulton Counties, Georgia. JAMA 1988;260(22):3253-5. http://dx.doi.org/10.1001/jama.1988.03410220023007

Available online at http://www.thepcrj.org 


\section{Appendix 1. Questionnaire}

Date:

Gender:

Date of birth:

Age:

Do you belong to one of the following groups? If so, please colour the bullet(s).

O People with chronic lung problems ( e.g. Chronic Obstructive Pulmonary Disease, asthma, ...)

O People with chronic heart problems ( e.g. heart attack, angina, arrhythmia, valve problem, ...)

O People with chronic liver problems (e.g. chronic hepatitis, cirrhosis, ...)

O People with chronic kidney problems (e.g. kidney failure, dialysis)

O Diabetes patients

O People with chronic problems of their immune system (e.g.chemotherapy, radiotherapy, ...)

O Employee in the health sector

O Pregnant woman - second or third trimester

O I do not belong to any of these groups

Have you ever received a flu vaccine in the past?

$\mathrm{O}$ Yes

O No

O I do not know

Do you want to be informed about the possibility of flu vaccination?

O Yes,

If yes, please continue on the next page.

(Even if you are vaccinated annually)

(Even if you do not belong to any of the groups mentioned above)

O No, not even in the future.

You have completed the questionnaire, and may deposit it in the letter box or hand it over to your physician. 
Appendix 1. Questionnaire continued

How would you like to be informed about the possibility of flu vaccination?

Please indicate your top 3 of the 14 following possibilities ( $A$ to $\mathrm{N}$ )

\begin{tabular}{|c|c|}
\hline \multicolumn{2}{|c|}{ * By your family physician. } \\
\hline B & - By letter delivered via regular post, but not yet including a prescription \\
\hline C & - By letter delivered via regular post, already including a prescription \\
\hline D & - By phone \\
\hline $\mathrm{F}$ & - By posters and flyers in the waiting room \\
\hline \multicolumn{2}{|c|}{ * By your pharmacist. } \\
\hline G & - The pharmacist should personally discuss this with you during a visit to the pharmacy \\
\hline $\mathrm{H}$ & - By posters and flyers in the pharmacy \\
\hline \multicolumn{2}{|c|}{ * By the local authorities. } \\
\hline J & - By letter send to all citizens \\
\hline \multicolumn{2}{|c|}{ * Via the media. } \\
\hline K & - In papers and magazines \\
\hline $\mathrm{L}$ & - Via the radio \\
\hline M & - Via television \\
\hline \multicolumn{2}{|c|}{ * By someone else or in another manner. } \\
\hline $\mathrm{N}$ & $\begin{array}{l}\text { If you prefer to be informed in any other way not listed above, you may describe it here and include it in your } \\
\text { personal top } 3\end{array}$ \\
\hline
\end{tabular}

Personal top 3: (please fill in your personal top 3 )

Your first choice is:

Your second choice is:

Your third choice is:

Thank you for your cooperation. You may deposit the questionnaire in the letter box or hand it over to your physician. 